\title{
EVALUATION OF THE SHORT TERM OUTCOME OF UNILATERAL URETHRAL MOBILIZATION COMPARED TO CIRCUMFERENTIAL URETHRAL MOBILIZATION FOR THE MANAGEMENT OF BULBAR URETHRAL STRICTURE
}

\author{
KARTIK CHANDRA GHOSH ${ }^{1}$, MD. MIZANUR RAHMAN ${ }^{1}$, MD. SHAFIQUL ALAM CHOWDHURY ${ }^{1}$, PRODUYT \\ KUMAR SAHA ${ }^{1}$, MOHAMMED MIZANUR RAHMAN ${ }^{2}$, AKM MUSA BHUIYAN ${ }^{1}$
}

${ }^{1}$ Department of Urology, Dhaka Medical College, Dhaka, Bangladesh, ${ }^{2}$ Department of Urology, National Institute of Kidney Diseases \& Urology, Dhaka, Bangladesh.

\begin{abstract}
Objective: To evaluate and compare the outcome of buccal mucosal graft urethroplasty of unilateral and circumferential urethral mobilization for the management of bulbar urethral stricture.

Methods: Seventy patients having bulbar urethral strictures admitted in the Department of Urology, Dhaka Medical College Hospital, Dhaka between January 2010 to December 2011. Patients were divided into two groups. Group-I, underwent unilateral urethral mobilization, and Group-II, underwent circumferential urethral mobilization for buccal mucosa graft urethroplasty. All patients were followed up at least six months. The statistics used to analyze the data were descriptive statistics, and $p$ value $<0.05$ was considered as significant.

Results: Mean $\pm S D$ of age in Group-II and Group-I were $41.1 \pm 9.2$ and $37.4 \pm 8.2$ years respectively. All the baseline findings were identically distributed between the groups. Comparison of outcome at month 3 showed that peak urinary flow rate increased from their baseline figures, but the increase was significantly more in the unilateral group than that in the circumferential group (21.2 \pm 1.2 vs. $\left.18.9 \pm 2.0 Q_{\max } p=<0.001\right)$. After 6 months, evaluation showed that the peak urinary flow rate significantly higher in Group-I, than that in Group-II, $(24.2 \pm 2.9$ vs. $21.9 \pm 3.3, p<0.001)$. The voided urine volume was also significantly higher in Group-l, than that in Group-Il (330.8 \pm 50.1 vs. $294.5 \pm 46.1 \mathrm{ml}, p=$ 0.004). Consequently, PVR was lower in the former group than that in the latter group $(11.6 \pm 3.3$ vs. $14.1 \pm 2.9 \mathrm{ml}, p=0.002)$. Complications in unilateral urethral mobilization had a significantly lower (20\%) than that of circumferential urethral mobilization(45.71\%) $(p=0.024)$.

Conclusion: Buccal mucosa grafting is a versatile and effective treatment for the anterior urethral stricture, and the outcome is excellent following unilateral urethral mobilization in experienced hands.
\end{abstract}

Key words: Buccal Mucosal Graft, Unilateral, Circumferential, Urethral mobilization.

Bangladesh J. Urol. 2016; 19(1): 32-37

Introduction:

The term 'urethral stricture' refers to scarring process involving the spongy erectile tissues of the corpus spongiosum causing spongiofibrosis that is composed of dense collagen and fibroblasts. As these scars

Correspondence: Kartik Chandra Ghosh, Department of Urology, Dhaka Medical College Hospital, E-mail:kcghoshurodoc@gmail.com contract, narrowing occurs in the urethral lumen which restricts urine flow and causes dilatation of the proximal urethra.

Further obstruction may cause secondary complications in the urinary tract like; urethritis, prostatitis, periurethral abscess, urethrocutaneous fistula, hypertrophied bladder muscle, and secondary bladder stones. Finally, chronic 
urinary stasis due to severe stricture causes hydroureteronephrosis, and even patient may present with renal failure[1,2].

Successful male urethral reconstruction poses a continuing challenge in modern urology. Numerous surgical techniques have been described to repair bulbar urethral stricture according to the stricture length and location. Urethral reconstruction with excision of the stricture segment and end-to-end anastomosis is successful in more than $95 \%$ of patients with a stricture of up to $2 \mathrm{~cm}$ in length in proximal bulbar urethra. Patients with long anterior urethral stricture $(>2 \mathrm{~cm})$ is suitable for dorsal or ventral onlay graft urethroplasty because end-to-end urethroplasty in such cases cause postoperative chordee formation[3,4]. Continuous efforts are made in different centers over the last 50 years to fine out an ideal procedure of management with maximum benefits and even in one stage urethroplasty[5,6].

Buccal mucosa is familiar to reconstructive urologists, and is the most preferred graft for reconstruction of long bulbar urethral stricture, but placement of a graft either ventraly, dorsaly or lateraly is still controversial[7]. Barbagli et al. [8] showed dorsal onlay graft has obvious advantages over the ventral onlay graft urethroplasty. Dorsal placement of buccal graft on the corporal bodies provides the advantages of mechanical support, vascular supply leading to neovascularisation, maintenance of caliber of a reconstructed urethra and decreased incidence of graft necrosis, urethrocutenious fistula, saccule formation which are commonly seen in ventral onlay grafts urethroplasty[9]. In the dorsal onlay graft urethroplasty, the bulbar urethra is mobilized circumferentially and rotated 180 degrees and opened along its dorsal surface[10].

Recently, a surgical technique is described to preserve the vascular supply on one side of the bulbospongiosum muscle, the central tendon of the perineum, and the perineal nerves using a dorsolateral onlay urethroplasty by unilateral urethral mobilization, so ischaemia, nerve damage to the bulbospongiosum muscle, and the perineal nerves can be avoided and improve the success rate[11,12]. The study has been carried out to evaluate the outcome of unilateral urethral mobilization for the management BMG urethroplasty compared to circumferential urethral mobilization.

\section{Materials and Methods}

The present study was conducted to evaluate and compare the outcome of unilateral and circumferential urethral mobilization for the management of bulbar urethral stricture in terms of the improvement of peck urinary flow rate $\left(Q_{\max }\right)$, voided volume of urine, $P V R$, possible complications and rate of recurrence of stricture. In this prospective study, 70 consecutive patients having bulbar urethral stricture were selected as per selection criteria in the Department of Urology, Dhaka Medial College Hospital, Dhaka. The patients were divided into two groups on the basis of alternate case selection. In group-I, 35 patients underwent unilateral urethral mobilization, and in Group-II, 35 patients underwent circumferential urethral mobilization for BMG urethroplasty.

\section{Preparation of the Patients}

Thorough wash of the genitalia and perineum was given with povidone iodine scrub once daily for three days by patient himself. Fresh soap bath was taken in the morning of operation.

\section{Operative procedure}

All patients were given general anesthesia. Operations were performed by two-team approach. One team harvested the buccal mucosa from the inner cheek and lower lip. The donor site was closed with 4-0 chromic catgut in running suture, and second team exposed the stricture.

\section{Surgical technique of unilateral urethral mobilization}

The patient was placed in a lithotomy position. The BMG was harvested from the cheek according to the standard technique. A midline perineal incision was made. The bulbar urethra was dissected from the corpora cavernosa only along the left side, starting from the distal tract where muscles are absent leaving the bulbospongiosum muscle and the central tendon of the perineum intact. Along the right side, the urethra remained attached to the corpora cavernosa for its full length, thus preserving its lateral blood supply. On the left side, the urethra was partially rotated, and the lateral urethral surface was underlined. The distal stenosis was identified, the dorsal urethral surface was incised along the midline, and the urethral lumen was exposed. The stricture was then incised along its entire length by extending the urethrotomy distally and proximally. The BMG was trimmed to an appropriate size according to the length and width of the urethrotomy, The two apices of the graft were sutured to the proximal and distal apices of the urethrotomy. The right margin of the oral graft is sutured to the left margin of the urethral mucosal plate. A Foley 16 Fr silicone catheter was inserted. The bulbar 
urethra with the intact bulbospongiosum muscle was rotated to its original position over the graft. Interrupted $4 / 0$ polyglactin sutures are used to stabilize the urethral margins onto the corpora cavernosa over the graft on the left side. The graft is completely covered by the urethra, and wound was closed in layers.

\section{Surgical technique of circumferential urethral mobilization}

The patient was placed in lithotomy position. A midline perineal incision was made. The bulbocavernous muscles were separated in the midline, and patients with proximal urethral stricture, the central tendon of the perineum was dissected. The entire urethra was freed from the bulbocavernous muscles. The bulbar urethra was dissected from the corpora cavernosa. The urethra was rotated 180 degree, and the distal extent of the stenosis was identified by gently inserting a $16 \mathrm{Fr}$ catheter with a soft round tip until it met resistance. The dorsal urethral surface was incised in the midline until the catheter tip and urethral lumen were exposed. The stricture was incised along its entire length by extending the urethrotomy distally and proximally. The BMG is trimmed to an appropriate size according to the length and width of the urethrotomy. The two apices of the graft were sutured to the proximal and distal apices of the urethrotomy. A Foley $16 \mathrm{Fr}$ silicone catheter was inserted. The bulbar urethra was rotated to its original position over the graft. Three interrupted 4-0 polyglactin sutures for each side were used to stabilize the urethral margins to the corpora cavernosa over the graft, and the graft was completely covered by the urethra. Wound was closed in layers. A suction drain is left in place for one day.

\section{Postoperative Care}

Mild pressure dressing was applied over the wound to prevent haematoma. The drain was removed after 24 hours, and patients were discharged after 3-5 days. The catheter was kept in situ for 3 weeks in all cases. A pericatheter urethrogram was performed after 3 weeks. If there was no periurethral leakage, the catheter was removed. Urethral catheters were kept in situ for further one week or more in patients, if any leakage was noted.

\section{Follow up Schedule and Evaluation}

All patients were followed up for at least six months by history, physical examinations, and investigations. RGU and MCU was done when peak flow was $<15 \mathrm{ml} / \mathrm{sec}$ in uroflowmetry. Urethroscopy was done at $3^{\text {rd }}$ and $6^{\text {th }}$ month. Outcome was evaluated on the basis of post- operative complications, findings of pericatheter urethrogram, Uroflowmetry, RGU and MCU and Urethrocystoscopy. Successful reconstruction was defined as normal voiding; urine flow rate is e" $15 \mathrm{ml} / \mathrm{sec}$ without need for any postoperative procedure, including dilatation.

\section{Statistical Analysis:}

Data were analyzed using SPSS version 13 , and the descriptive statistics were used to analyze the data, and the Student's t-test, Chi-square test, ANOVA, and Fisher exact test were used. A $p$ value $<0.05$ was considered as significant.

\section{Results:}

Seventy patients (35 patients underwent unilateral urethral mobilization, and 35 patients underwent circumferential urethral mobilization) having bulbar urethral strictures were evaluated to compare the shortterm outcome of the two techniques of urethral mobilization for the management of bulbar urethral stricture. Patients $\geq 40$ years old were higher in the circumferential group compared to unilateral group. The mean age in the former and the latter groups were being $41.1 \pm 9.2$ years and $37.4 \pm 8.2$ years respectively. No significant difference was found between the groups in terms of causes of stricture. Preoperatively, a large proportion of patients in the circumferential group complained of poor urinary stream and LUTS than those in the unilateral group $(97.1 \%$ vs. $77.1 \%$, and $88.6 \%$ vs. $77.1 \%$, respectively). Urethral discharges were almost identically distributed between unilateral and circumferential groups ( $40 \%$ vs. $45.7 \%$ ). The incidence of acute urinary retention was higher in the former group than those in the latter group $(34.3 \%$ vs. $17.1 \%, p=$ 0.101 and $34.3 \%$ vs. $5.7 \%, p=0.003$ ). The mean length of stricture and peak urinary flow rate was higher in unilateral group compared to circumferential group (3.6 \pm 0.8 vs. $3.5 \pm 0.7 \mathrm{~cm}$ and $7.8 \pm 1.5$ vs. $7.6 \pm 1.5 \mathrm{Q}_{\max }$ respectively). However, mean volume of voided urine and PVR were considerably higher in the latter group than those in the former group ( $212.5 \pm 57.7$ vs. $210.5 \pm 61.8$ $\mathrm{ml}$ and $59.4 \pm 6.7$ vs. $57.4 \pm 6.2 \mathrm{ml}$ respectively). Over $45 \%$ of patients in unilateral group had urinary tract infection compared to $40 \%$ in the circumferential group. All the baseline findings were identically distributed between groups (Table-I). Over two-third (68.6\%) of the patients in unilateral group and $71.4 \%$ in the circumferential group had longer stricture $(>3 \mathrm{~cm}$ ) (Figure 1). Comparison of immediate outcome showed that in both groups the peak urinary flow rate increased from their baseline figures, 


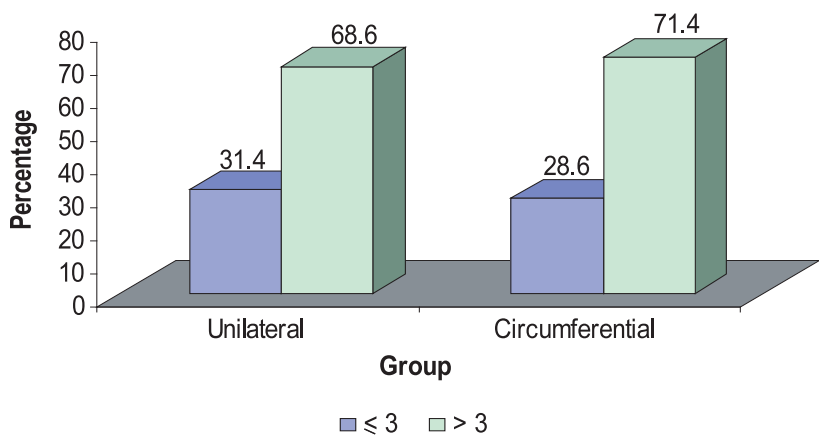

Fig.-1: Comparison of length of stricture between two groups

and there was no significant difference between the groups in terms of peak urinary flow rate $(15.3 \pm 1.2$ vs. $\left.15.9 \pm 1.8 Q_{\max }\right)$. The voided urine volume was significantly higher in circumferential group than that in unilateral group ( $354.3 \pm 40.4$ vs. $328.8 \pm 50.1 \mathrm{ml})$. Comparison of outcome at month 3 showed that a significant difference in peak urinary flow rate in the unilateral group than that in the circumferential group $\left(21.2 \pm 1.2\right.$ vs. $\left.18.9 \pm 2.0 \mathrm{Q}_{\max }\right)$. However, no significant difference was observed between the groups in respect to voided urine volume $(331.8 \pm 25.1$ vs. $340.3 \pm 40.4 \mathrm{ml}$ ) (Table-II). Uroflowmetric evaluation after 6 months of intervention showed that the peak urinary flow rate increased further in both unilateral and circumferential groups with former showing more increase than the latter $(24.2 \pm 2.9$ vs. $21.9 \pm 3.3)$. The voided urine volume was also significantly higher in the unilateral group than that in the circumferential group (330.8 \pm 50.1 vs. $294.5 \pm 46.1 \mathrm{ml})$. Consequently, PVR was lower in the former group than that in the latter group (11.6 \pm 3.3 vs. $14.1 \pm 2.9 \mathrm{ml}$ ) (TableIII). Complications like wound infection, urethrocutaneous fistula, recurrence of stricture and optical instrumentation to dilate the stricture were less common in the former group than that in the latter group although the differences were not statistically significant (Table-IV).

\section{Table-I}

Comparison of baseline findings between two groups

\begin{tabular}{lccc}
\hline Baseline findings & \multicolumn{2}{c}{ Group } & p- \\
& $\begin{array}{c}\text { Group-I } \\
(\mathrm{n}=35)\end{array}$ & $\begin{array}{c}\text { Group-II } \\
(\mathrm{n}=35)\end{array}$ & value \\
\hline Length of stricture $^{\#}$ & $3.6 \pm 0.8$ & $3.5 \pm 0.7$ & 0.938 \\
Peak urinary flow rate\# $^{\#}$ & $7.8 \pm 1.5$ & $7.6 \pm 1.5$ & 0.589 \\
Voided urine volume $^{\#}$ & $210.5 \pm 61.8$ & $212.5 \pm 57.7$ & 0.840 \\
PVR $^{\#}$ & $57.4 \pm 6.2$ & $59.4 \pm 6.7$ & 0.829 \\
Urinary tract infection* $^{*}$ & $21(45.7)$ & $14(40.0)$ & 0.629 \\
\hline
\end{tabular}

\# Data were analysed using Student's t-Test and presented as mean $\pm S D$. Figures in the parentheses indicate corresponding percentage. * Data were analysed using Chi-square $\left(\chi^{2}\right)$ Test.
Table-II

Comparison of outcome after 3 months of operation between two groups

\begin{tabular}{lccc}
\hline Outcome variables & \multicolumn{2}{c}{ Group } & P - \\
& $\begin{array}{l}\text { Group-I } \\
(\mathrm{n}=35)\end{array}$ & $\begin{array}{c}\text { Group-II } \\
(\mathrm{n}=35)\end{array}$ & value $^{\#}$ \\
\hline $\begin{array}{l}\text { Peak urinary flow } \\
\text { rate }\left(\mathrm{Q}_{\text {max }}\right)^{\#}\end{array}$ & $21.2 \pm 1.2$ & $18.9 \pm 2.0$ & $<0.001$ \\
$\begin{array}{l}\text { Voided urine } \\
\text { volume }(\mathrm{ml})^{\#}\end{array}$ & $331.8 \pm 25.1340 .3 \pm 40.4$ & 0.313 \\
\hline
\end{tabular}

\#Data were analysed using Student's t-Test and presented as mean $\pm \mathrm{SD}$.

Table-III

Comparison of outcome at month 6 of operation between two groups

\begin{tabular}{|c|c|c|c|}
\hline \multirow[t]{2}{*}{ Outcome variables } & \multicolumn{2}{|c|}{ Group } & \multirow{2}{*}{$\begin{array}{c}\mathrm{p}- \\
\text { value }^{\#}\end{array}$} \\
\hline & $\begin{array}{l}\text { Group-I } \\
(n=35)\end{array}$ & $\begin{array}{l}\text { Group-II } \\
(n=35)\end{array}$ & \\
\hline $\begin{array}{l}\text { Peak urinary flow } \\
\text { rate }\left(Q_{\text {max }}\right)^{\#}\end{array}$ & $24.2 \pm 2.9$ & $21.9 \pm 3.3$ & $<0.00$ \\
\hline $\begin{array}{l}\text { Voided urine } \\
\text { volume }(\mathrm{ml})^{\#}\end{array}$ & $330.8 \pm 50.1$ & $294.5 \pm 46.1$ & 0.004 \\
\hline $\operatorname{PVR}(\mathrm{ml})^{\#}$ & $11.6 \pm 3.3$ & $14.1 \pm 2.9$ & 0.002 \\
\hline
\end{tabular}

\# Data were analysed using Student's t-Test and was presented as mean \pm SD.

Table -IV

Complications encountered by the patients of two groups

\begin{tabular}{lccc}
\hline Complications & \multicolumn{2}{c}{ Group } & p-value $^{\#}$ \\
& $\begin{array}{l}\text { Group-I } \\
(\mathrm{n}=35)\end{array}$ & $\begin{array}{c}\text { Group-II } \\
(\mathrm{n}=35)\end{array}$ & \\
\hline Bleeding $^{*}$ & $4(11.4)$ & $10(28.6)$ & 0.073 \\
Wound infection* $^{*}$ & $6(17.1)$ & $12(34.3)$ & 0.101 \\
Urethrocutaneous fistula $^{\#}$ & $1(2.9)$ & $3(8.6)$ & 0.307 \\
Recurrence of stricture $^{\#}$ & $3(8.6)$ & $6(17.1)$ & 0.239 \\
Optical instrumentation $^{\#}$ & $3(8.6)$ & $6(17.1)$ & 0.239 \\
\hline
\end{tabular}

* Data were analysed using Chi-square $\left(\chi^{2}\right)$ Test.

\# Data were analysed using Fisher's Exact Test.

\section{Discussion:}

The present quasi-experimental study was conducted in the Department of Urology, Dhaka Medical College Hospital, Dhaka between January 2010 to December 2011.

In the present study, no significant difference was found between the two groups in terms of mean age, length of 
stricture, causes of stricture, and clinical presentations $(p>0.05)$. The age of the patients corresponds with the study of Barbagli et al. (2008)[13]. In different international series of substitution urethroplasty of anterior urethral stricture, the patients were selected with a stricture length of $>2 \mathrm{~cm}$ at bulbar part[14,15]. Moreover, the causes of stricture in various international series are more or less same with the present study. Comparison of causes of stricture does not show any significant difference between the groups $(P>0.05)$.

In the present study the base line findings, were identically distributed between the two groups $(p=0.938$, $p=0.589, p=0.840, p=0.829$ and $p=0.629$ respectively). Comparison of immediate outcome showed that in both groups the peak urinary flow rate increased from their baseline figures, but no significant difference was observed (15.3 \pm 1.2 vs. $\left.15.9 \pm 1.8 Q_{\max }, p=0.104\right)$. However, the voided urine volume was significantly higher in group-II than that in group-I ( $354.3 \pm 40.4$ vs. $328.8 \pm 50.1$ $\mathrm{ml}, \mathrm{p}=0.023$ ).

Comparison of outcomes at $3^{\text {rd }}$ and $6^{\text {th }}$ month of intervention showed a significant difference of peak urinary flow rate between two groups $(21.2 \pm 1.2$ vs. $18.9 \pm 2.0 Q_{\text {max }}, p=<0.001$ and $24.2 \pm 2.9$ vs. $21.9 \pm 3.3$, $p<0.001$ respectively). there was no significant difference in-terms of voided urine volume at 3 month $(331.8 \pm 25.1$ vs. $340.3 \pm 40.4 \mathrm{ml}, \mathrm{p}=0.313$ ), however, it was significantly higher in group-I than group-II at 6 month follow up (330.8 \pm 50.1 vs. $294.5 \pm 46.1 \mathrm{ml}, \mathrm{p}=0.004)$. In the series of Palmintiri et al. (2008)[16] using unilateral urethral mobilization, post operative peak urinary flow of successful patients was $31.02 \mathrm{ml} / \mathrm{s}$ versus the preoperative average peak urinary flow of $7.64 \mathrm{ml} / \mathrm{s}$. Another study reported peak flow rate ranged between $18-29 \mathrm{ml} / \mathrm{sec}$ (mean 21) after successful operation of bulbar uerthral stricture using circumferential urethral mobilization[17]. Six patients in group-I developed wound infection which was subsided with regular dressing, and fistula was observed in $1(2.9 \%)$ patient, who was cured spontaneously with two weeks further catheterization. Three patients (8.6\%) develop recurrence, which was managed by internal urethrotomy. In group-II 12 patients developed wound infection and 3 patients developed fistula which were managed as in previous group. Six patients $(17.1 \%)$ developed recurrence, which was also managed by internal urethrotomy. One study reported $11 \%$ of recurrent stricture of dorsal onlay buccal mucosa graft urethroplasty of bulbar urethral stricture[18].
In different studies from 1998 to 2008 reported a success rate ranged from $65.8 \%$ to $90 \%$ with circuferential urethral mobilization for penile or buccal mucosa graft urethroplasty of bulbar urethra with a complications rate ranged from 3 to $25 \%$ and reoperation rate ranged from 2 to $8 \%$ which correspond the present study of using circumferential urethral mobilization[17]. Muscle and nerve sparing bulbar urethroplasty of six patients showed no postvoiding dribbling, semen sequestration, and no recurrence in 6 to 12 months after surgery[19]. In various studies of BMG urethroplasty using circumferential urethral mobilization Kene et al. [20] reported a success rate $94.3 \%$, Pansadoro et al. [21] reported $96 \%$ and Andrich and Mundy[22] reported $89 \%$.

A success rate of $87.5 \%$ with a recurrence of original disease of $12.5 \%$ reported by Kulkarni et al. [12] in 32 patients underwent circumferential urethral mobilization of BMG urethroplasty which is similar to the results of present study. They also reported their previous experiences, in Kulkarni et al. (2003)[23] an 83.5\% success rate, and the dorsal BMG urethroplasty showed a $77.3 \%$ success rate. In a series using a new vascular, muscle and nerve-sparing procedure, the success rate was $92 \%$ which represent the results of present study.

In the present study in group-I BMG urethroplasty, success rate was $91.4 \%$ and in group-II BMG urethroplasty group success rate was $82.85 \%$. There is an encouraging outcome in group-I and significant difference was observed between the groups in terms of the peak urinary flow rate, voided volume of urine and PVR. Although overall complication rates in group-II were higher, no significant difference was observed between the groups in terms of postoperative complications and recurrence of disease.

\section{Conclusion:}

Buccal mucosa grafting is a versatile and effective treatment for the anterior urethral stricture, and in experienced hands, the outcome is excellent. The outcome of unilateral urethral mobilization is better than circumferential urethral mobilization for BMG urethroplasty of bulbar urethral stricture. Long-term followup and large sample are necessary to clarify the outcome which is related to urethral mobilization using BMG.

\section{Conflict of Interest : None declared}

\section{References:}

1. Jordan GH and Schlossberg SM. Surgery of the penis and urethra. Campbell's-Walash Urology, $9^{\text {th }}$ eds, 2007, Saunders, Philadelphia. 
2. McAninch, JW. Disorders of the penis and male urethra. Smith's general urology. $17^{\text {th }}$ eds, 2008, McGraw-Hill Co, Philadelphia, New York.

3. Gupta NP, Ansari MS, Dogra PN, Tandon S. Dorsal buccal mucosal graft urethroplasty by a ventral sagittal urethrotomy and minimal access perineal approach for anterior urethral stricture. BJU Int 2004;93:1287-90.

4. Mangera A, Patterson JM, Chapple CR. A Systematic Review of Graft Augmentation Urethroplasty Techniques for the Treatment of Anterior Urethral Strictures. European Association of Urology 2011;59:797-814.

5. Barbagli G, Palminteri E, Guazzoi G, Canti CA. Bulbar urethroplasty using the dorsal approach: Current techniques. Int Braz J Urol 2003;29:15561.

6. Barbagli G, Stefani SD, Sighinolfi MC, Annino F, Micali S, Bianchi G. Bulbar urethroplasty with dorsal onlay buccal mucosal graft and fibrin glue. Eur Urol 2006;50:467-74.

7. Bhargava $S$ and Chapple CR. Buccal mucosal urethroplasty: is it the new gold standard. BJU Int 2004;93:1191-93.

8. Barbagli G, Stefani SD, Annino F, Carne CD, Bianchi G. Muscle- and nerve-sparing bulbar urethroplasty: a new technique. Eur Urol 2008;54:335-43.

9. Bhargava S, Chapple CR, Bullock AJ, Layton C, Macneil S. Tissue-engineered buccal mucosa for substitution urethroplasty. BJU Int 2004;93:807811.

10. Datta B, Rao MP, Acharya RL, Goel N, Saxena V, Trivedi S. Dorsal Onlay Buccal Mucosal Graft Urethroplasty in Long Anterior Urethral Stricture. International Braz J Urol 2007;33:181-87.

11. Chaudhary R, Jain N, Singh K, Singh HB, Chaudhary R, Biswas R. Dorsolateral onlay urethroplasty for pan anterior urethral stricture by a unilateral urethral mobilisation approach. BMJ case report 2011;10:1-7.

12. Kulkarni SB, Kulkarni JS, Kirpekar DV. A new technique of urethroplasty for balanitis xerotica obliteran. J Urol 2003;163(Suppl.):352-57.
13. Barbagli G, Guazzoni G, Lazzeri M. One-stage bulbar urethroplasty: retrospective analysis of the results in 375 patients. Eur Urol 2008; 53:828-33.

14. Peterson CA and Webster GD. Management 'of urethral stricture disease: developing options for surgical intervention. BJU Int 2004;94:971-76.

15. Dubey D, Kumar A, Mandhanim A, Srivastava A, Kapoor R, Bhandari M. 'Buccal mucosal urethroplasty: a versatile technique for all urethral segments. BJU Int 2005;95:625-29.

16. Palminteri E, Manzoni G, Berdondini E. Combined dorsal plus ventral double buccal mucosa graft in bulbar urethral reconstruction. Eur Urol 2008;53:81-90.

17. Barbagli G, Palminteri E, Lazzeri M, Guazzoni G. One-stage circumferential buccal mucosa graft urethroplasty for bulbous stricture repair. Urology 2003a;61:452-55.

18. Andrich DE and Mundy AR. Substitution urethroplasty with buccal mucosal-free grafts. J Urol 2001;165:1131-34.

19. Barbagli G, Morgia G, Lazzeri M. Retrospective outcome analysis of one-stage penile urethroplasty using a flap or graft in a homogeneous series of patients. BJU Int 2008;102:853-60.

20. Kane CJ, Tarman GJ, Summerton DJ. Multiinstitutional experience with buccal mucosa onlay urethroplasty for bulbar urethral reconstruction. J Urol 2002;167:1314-17.

21. Pansadoro V, Emiliozzi P, Gaffi M. Buccal mucosa urethroplasty for the treatment of bulbar urethral strictures. J Urol 1999;161:1501-03.

22. Andrich DE and Mundy AR. Urethral stricture and their surgical management. BJU Int 2000;86: 571-80.

23. Kulkarni S, Barbagli G, Sansalone S, Lazzeri M. One-sided anterior urethroplasty: a new dorsal onlay graft technique. BJU Int 2009;104:1150-55.

Abbreviations:

BMG : Buccal Mucosal Graft

MCU : Micturating Cystourethrogram

PVR : Post Void Residue of Urine

RGU : Retrograde Urethrogram 